\title{
The coming health crisis: indirect health effects of global climate change
}

\author{
Samuel S. Myers ${ }^{1 *}$ and Aaron Bernstein ${ }^{2}$
}

\author{
Addresses: ${ }^{1}$ Harvard Medical School, Mount Auburn Hospital Walk-In Center, 330 Mount Auburn Street, Cambridge, MA 02138, USA; \\ ${ }^{2}$ Harvard Medical School, Center for Health and the Global Environment, 401 Park Drive, 2nd Floor East, Boston, MA 02215, USA \\ * Corresponding author: Samuel S. Myers (sam_myers@hms.harvard.edu) \\ FI000 Biology Reports 20II, 3:3 (doi:10.3410/B3-3) \\ This is an open-access article distributed under the terms of the Creative Commons Attribution-Non Commercial License \\ (http://creativecommons.org/licenses/by-nc/3.0/legalcode), which permits unrestricted use, distribution, and reproduction in any medium, \\ provided the original work is properly cited. You may not use this work for commercial purposes. \\ The electronic version of this article is the complete one and can be found at: http://f $1000 . c o m / r e p o r t s / b / 3 / 3$
}

\begin{abstract}
Global climate change threatens the health of hundreds of millions of people. While much has been written about the direct impacts of climate change on health as a result of more severe storms, more intense heat stress, changes in the distribution of infectious disease, and reduced air quality, we are concerned that the indirect impacts of a disrupted climate system may be orders of magnitude more important in terms of the human suffering they cause. Because these indirect effects will result from changes in biophysical systems, which are inherently complex, there is significant uncertainty about their magnitude, timing, and location. However, the uncertainty that shrouds this issue should not be cause for complacency; rather it should serve as an organizing principle for adaptation to its ill effects.
\end{abstract}

Human activity is disrupting Earth's climate, and the rising emissions of greenhouse gases are accelerating that disruption. Carbon dioxide levels in the atmosphere exceed anything Earth has experienced in the past million years and are rapidly approaching levels not seen since the Eocene when there were no ice caps, sea level was $100 \mathrm{~m}$ above current levels, and there were crocodiles near the North Pole. Global temperatures have been rising steadily for nearly 40 years; the eight warmest years on record have occurred since 2001 and the global average land-surface temperature for the period January to September 2010 was the second warmest on record behind 2007. In addition to rising mean global surface temperatures, climatic disruption is causing other changes to the physical conditions of the planet. Among these are rising sea level and changes in the pattern of precipitation leading to more frequent droughts, floods, and forest fires, and more extreme storms. Some of the health consequences of climate change are straightforward: warmer temperatures, changes in the hydrologic cycle, increased ground-level ozone, and enhanced pollen production will increase exposure to heat stress, alter patterns of infectious disease, and compromise air quality. These and similar direct impacts of climate change have been well covered in the scientific literature.

However, we believe that there is another threat, one that is orders of magnitude more potent than those which have been emphasized to date. Here we argue that it is the indirect impacts of climate change-large-scale alterations to Earth's natural systems-that pose the greatest risk to human health. These changes are curtailing access to water and food and are undermining the very concept of stable homes, yet have received scant attention in the literature, including the report of Working Group II of the Intergovernmental Panel on Climate Change (IPCC) [1]. Enormous uncertainties surround predictions regarding how climate change may affect human well-being. Acknowledging these uncertainties is a critical component of designing optimal approaches to mediating the health impacts of climate change.

\section{Water}

Water scarcity is already a major global issue that carries heavy adverse health sequelae, and climate change will 
further destabilize access to fresh water. A sampling of four current crises illustrates the gravity of the situation. One: In the North China Plain, where half of China's wheat is grown, the water table is falling by as much as $3 \mathrm{~m}$ per year. Two: Certain states in India are using half of their electricity budget to pump water from depths as deep as $1 \mathrm{~km}$ to irrigate crops. Three: Roughly 300 million Chinese and Indians are eating food grown on "fossil" water that is not replenished. Four: In the Middle East and North Africa, current rates of freshwater use are equivalent to $115 \%$ of total renewable runoff. Given such unsustainable use around the world, the number of people living in water-scarce countries is expected to rise sixfold from 470 million to 3 billion between 1990 and 2025 .

Future trends are of even greater concern. Rapid human population growth combined with economic development begets increased water demand from homes, industry, and agriculture. In agriculture alone, the amount of water required to keep pace with global food demand roughly $2000-3000 \mathrm{~km}^{3}$-represents a tripling of water used for irrigation. This is water that, in many parts of the world, simply is not available.

The availability of adequate potable water is a pillar of public health without which human well-being falters. In addition to hindering food production, inadequate access to water and sanitation has direct effects on human health. Today, half of the urban populations of Africa, Asia, Latin America, and the Caribbean suffer from diseases associated with inadequate access to water and sanitation, and roughly 1.7 million people die every year from these diseases.

Climate change is expected to exacerbate water scarcity in several ways. Scientists predict that the hydrologic cycle will be altered with, generally speaking, wet areas becoming wetter while dry areas become dryer. Precipitation will likely fall in greater amounts and cause more rapid runoff. Heavy precipitation events and associated runoff may make water supplies less reliable and may also make conditions favorable to outbreaks of water-borne disease. In the United States, for example, over $50 \%$ of water-borne disease outbreaks in the second half of the 20th century were preceded by precipitation events that were above the 90th percentile [2].

Warmer temperatures will also increase evapotranspiration, increasing water requirements for agriculture. At the same time, the availability of water during the height of the growing season may be less, owing to earlier melting of winter snowpack in the spring, leaving less water for summer irrigation. Agricultural systems dependent on glacial melt, such as the Andean nations of South America or much of Asia that receives water from the Tibetan plateau, may suffer such a fate as glaciers melt away. As these glaciers dwindle, they will provide ever less dry-season water flow into many of the world's great rivers. The Indus River, for example, receives $40-50 \%$ of its dry-season flow from glaciers that are rapidly receding. Finally, sea-level rise and more extreme storms will lead to coastal inundation and intrusion of salt water into freshwater aquifers, further reducing coastal freshwater supply.

\section{Nutrition}

Perhaps even more problematic to human welfare in the coming century than a further diminution in the availability of fresh water is the impact of climatic disruption on the supply of food. As with water, global access to food is already tenuous. In 2009, the number of people suffering from protein-calorie malnutrition exceeded 1 billion after reaching a low of around 830 million in the 1990s (Figure 1). In poor countries around the world, malnutrition underlies roughly one-third of the entire burden of disease, and roughly 2 to 3 billion people-almost half the human population-already suffer from micronutrient deficiencies.

Looking forward, farmers around the world will need to double agricultural production by 2050 in order to keep up with demand from a growing and more affluent human population that aspires to a more meat-based diet. This doubling of output will need to occur despite headwinds that already strain agricultural productivity. Water scarcity, as discussed above, is a major constraint to increasing agricultural production. In addition,

Figure I. Undernourished population (total and as share of world population, 1990-2009)

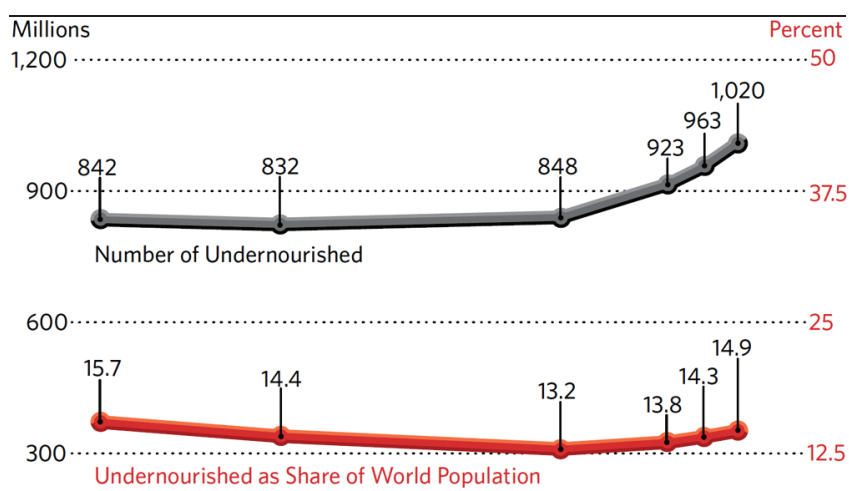

\begin{tabular}{cccccc} 
& & \multicolumn{3}{c}{ Source: FAO, UN Population Division } \\
\hline 1990 & 1994 & 1998 & 2002 & 2006 & 2010
\end{tabular}


roughly one-third of the Earth's land surface suffers from land degradation from the combined effects of soil erosion, salinization, nutrient depletion, and desertification. Finally, the rise of the biofuels industry-evidenced in the diversion of one-quarter of the US grain harvest to biofuel production-is generating enormous demand for grain. By increasing grain demand and, as a consequence, demand for arable land and irrigation, growing grains as biofuel feedstock pits human food needs against biofuel production.

Amid rapidly rising demand for food, increasing environmental pressures on food production, and growing human malnutrition, climate change additionally compromises both agricultural yields and the nutritional quality of the crops produced. Agricultural productivity is well known to be sensitive to changes in growing season temperatures. Observational, longitudinal, and modeling studies all confirm that a $1^{\circ} \mathrm{C}$ rise in temperature corresponds to roughly a $10 \%$ reduction in yield of the major grains [3-5]. As temperatures rise $2-6^{\circ} \mathrm{C}$ over the next century, the reduction in agricultural yield will depend, in part, on our capacity to adapt and, in part, on how temperature variability changes; but, in general, yields are expected to drop.

Climate change has further relevance to agricultural yields. As discussed above, climate change is expected to alter the timing and quantity of water available for agriculture while increasing the needs of plants as temperatures rise. Increased production of ground-level ozone curtails agricultural yields, as ozone is a potent plant toxin. When ozone concentrations reach $30-45 \mathrm{ppb}$ (parts per billion), yield losses for the major grains approach $10-40 \%$. By 2030, mean annual ozone concentrations in South Asia are expected to exceed $50 \mathrm{ppb}$. Increasingly intense tropical cyclones, sea level rise, more frequent forest fires, droughts, and floods will also conspire to diminish local harvests.

Despite strong evidence that climate change will increase the risk of numerous challenges to agricultural production, the net effect of climate change on global food production is difficult to quantify. Little is known, for example, about how climate change may alter the relationships between plants and their pests and pathogens, though several worrying examples indicate that climate change may promote infestations of plant pests, as higher winter minimum temperatures enable insects to overwinter more effectively. Also poorly understood is how climate change will impact the extent and pattern of cloud cover which, to some degree, determines the solar radiation available to plants for photosynthesis.
In addition to these impacts on the quantity of food produced, it appears that rising concentrations of atmospheric carbon dioxide also affect nutritional quality. Grains grown at elevated concentrations of carbon dioxide appear to have reduced concentrations of protein, iron, zinc, and perhaps other nutrients. As with other examples already cited in this article, these potential decrements in plant nutritional content are of particular concern given the current state of affairs: iron and zinc deficiency account for roughly 63 million years of life lost annually, and the major grains are a critical source of these nutrients for many populations around the world $[6,7]$. Taken together, these additional threats to food production may very well have extensive impacts on human nutrition and global health.

\section{Displacement}

Population displacement may be the final common pathway for many of the climate change impacts discussed above. Regional changes in precipitation leading to increased droughts and flooding, increased incidence of natural disasters like tropical cyclones and forest fires, local crop failures, and severe water scarcity are all likely to force people around the world to abandon their homes (Figure 2). In addition to these threats, coastal vulnerability puts many people at risk for displacement. More than one-third of the human population lives in coastal areas and on small islands that are within $100 \mathrm{~km}$ of the shore and less than $50 \mathrm{~m}$ above sea level. The combination of sea-level rise, increasingly intense storms, and destruction of coastal barriers (mangroves, wetlands, vegetated dunes, and coral reefs) leaves these populations extremely vulnerable. By 2050 an estimated 200 million to 1 billion

Figure 2. Category 5 natural disasters (number of disasters, 1980-2008)

\begin{tabular}{ll}
\hline Number of Events & Source: Munich Re
\end{tabular}

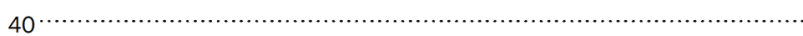

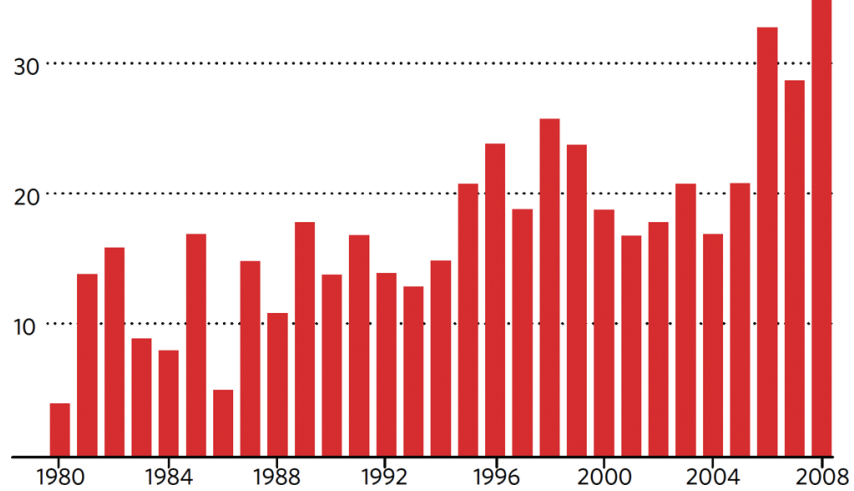


people may be displaced due to climate change. These estimates are highly uncertain in part because many of the biophysical changes that contribute to displacement remain hard to quantify $[8,9]$.

Despite this uncertainty, a significant fraction of the human population will undoubtedly be displaced in this century, and displaced persons face stark health realities. Nonimmune populations migrating into endemic areas are more susceptible to a variety of infectious diseases. Poor housing, sanitation, and access to safe drinking water combined with poor nutrition lead to disease epidemics, particularly diarrheal disease, measles, and acute respiratory infections. Malnutrition plagues displaced populations, with rates as high as $50 \%$ seen in refugee populations in Africa [10]. In addition to infectious disease and malnutrition, displaced people suffer from high rates of violence, sexual abuse, and mental illness. Post-traumatic stress disorder has been diagnosed in 30-75\% of resettled refugee children and adolescents [11]. Finally, displacement may lead to civil strife and violent conflict as large numbers of people with few resources move into areas where they frequently are not welcome.

\section{Living with uncertainty}

There is no doubt that climate change will have important impacts on human health, but we are uncertain about what those impacts will be and where and when they will be most severe. The most consequential health effects of climate change will come about from interactions between biophysical changes to the natural environment, demographic trends, and human adaptations (Figure 3). The biophysical changes-such as temperature variability or sea level rise-are difficult to predict with accuracy today, and the capacity for adapting to these changes is largely unknown.

But uncertainty about the exact timing, location, or magnitude of climate change impacts is no excuse for complacency. With evidence that climate change is already imposing a hefty health burden, the future climate, particularly if greenhouse gas releases into the atmosphere go unabated, portends health crises for hundreds of millions of people. Rather than be used as a rationale for inaction, the uncertainty inherent in climate science should serve as an organizing principle for adaptation to its ill effects. For example, uncertainty about future viable regions and conditions for agriculture requires a variety of new crop strains with traits such as heat and drought resistance. Changes in the timing of seasonal flow from melting snowpack or glaciers call for a dramatic increase in water-storage capacity for people depending on these flows for household use or irrigation. Insurance schemes allowing different countries or

\section{Figure 3. Complex relationships: altered environmental conditions and human health}

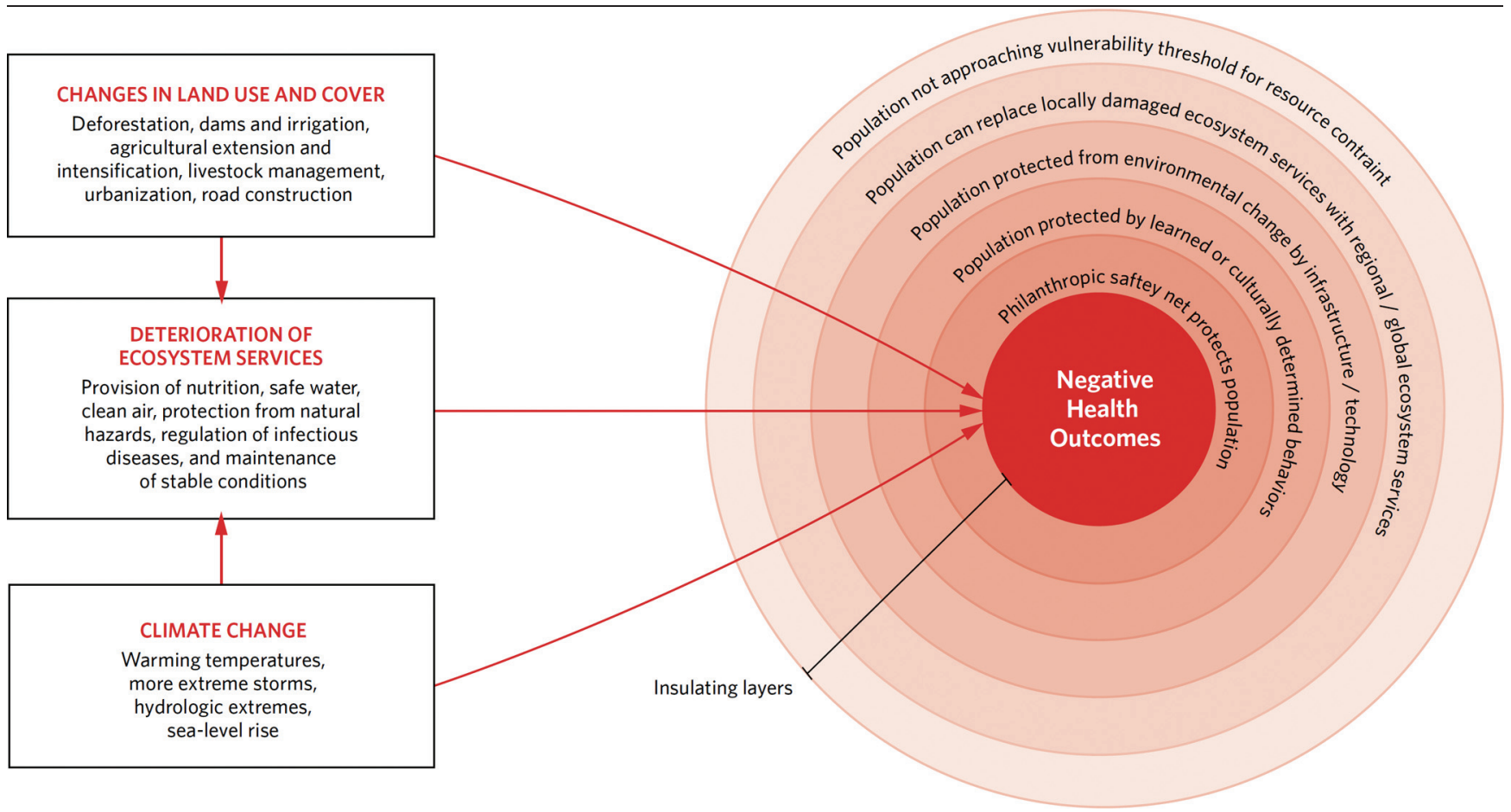


populations to pool their risk of crop failure and food insecurity might be enacted to blunt the toll of regional climatic disruption. Surveillance efforts should be designed that allow us to better detect changing distributions of infectious disease, water scarcity, or food insecurity early on so that resources can be efficiently redirected.

Never before have the consumption patterns of those in the wealthy countries of the world played such an important role in putting the health of the poor at greater risk. How the wealthy world responds to the moral imperative to help the developing world adapt to climate-change vulnerability will be a defining characteristic of this century.

\section{Competing interests}

The authors declare that they have no competing interests.

\section{References}

I. Parry ML, Canziani OF, Palutikof JP, van der Linden PJ, Hanson CE (Eds.): Climate Change 2007: Impacts, adaptation and vulnerability. Contribution of Working Group II to the Fourth Assessment Report of the Intergovernmental Panel on Climate Change. Cambridge, UK: Cambridge University Press; 2007.

2. Curriero FC, Patz JA, Rose JB, Lele S: The association between extreme precipitation and waterborne disease outbreaks in the United States, I 948- I 994. Am J Public Health 2001, 9 I: I I94-9.
3. Battisti DS, Naylor RL: Historical warnings of future food insecurity with unprecedented seasonal heat. Science 2009, 323:240-4

FI000 Factor 8

Evaluated by Evan DeLucia 28 Jan 2009

4. Lobell DB, Burke MB, Tebaldi C, Mastrandrea MD, Falcon WP, Naylor RL: Prioritizing climate change adaptation needs for food security in 2030. Science 2008, $319: 607-10$.

5. Peng S, Huang J, Sheehy JE, Laza RC, Visperas RM, Zhong X, Centeno GS, Khush GS, Cassman KG: Rice yields decline with higher night temperature from global warming. Proc Natl Acad Sci U S A 2004, I01:997|-5.

6. Caulfield LE, Black RE: Zinc Deficiency. In Comparative Quantification of Health Risks: Global and Regional Burden of Disease Attributable to Selected Major Risk Factors, Vol. I. Edited by Ezzati M, Lopez AD, Rodgers A, Marray CJL. Geneva: World Health Organization; 2004, 257-79.

7. Stoltzfus RJ, Mullany L, Black RE: Iron Deficiency Anemia. In Comparative Quantification of Health Risks: Global and Regional Burden of Disease Attributable to Selected Major Risk Factors, Vol. I. Edited by Ezzati M, Lopez AD, Rodgers A, Marray CJL. Geneva: World Health Organization; 2004, 63-209.

8. Johnstone LC: Planning for the inevitable, the humanitarian consequences of climate change. Presented at the 'Linking Climate Change Negotiations and Disaster Risk Reduction' Public Seminar. 12-13 November 2008; Copenhagen.

9. Warner K, Ehrhart C, de Sherbinin A, Adamo S, Chai-Onn T: In search of shelter: mapping the effects of climate change on human migration and displacement. New York, NY: Cooperative for Assistance and Relief Everywhere (CARE); 2009.

10. Toole MJ, Waldman RJ: Refugees and displaced persons. War, hunger, and public health. JAMA 1993, 270:600-5.

II. McCloskey LA, Southwick K: Psychosocial problems in refugee children exposed to war. Pediatrics 1996, 97:394-7. 